\title{
Língua, variação e livro didático: análise da abordagem da variação linguística em manuais didáticos do Ensino Médio
}

\author{
Rafael Petermann ${ }^{1}$
}

Luiz Henrique Alves ${ }^{2}$

\begin{abstract}
RESUMO
Este trabalho tem como objetivo analisar de que maneira três livros didáticos voltados para o Ensino Médio abordam as questões de variação linguística, verificando se, ao tratarem da temática, a concepção de língua como prática social é subjacente à abordagem do material. Para tanto, empreendeu-se uma pesquisa caracterizada como análise documental de caráter exploratório tendo como documentos de análise livros didáticos adotados em escolas públicas do interior do Paraná no PNLD 2015-2017, com foco para as unidades didáticas que tratam de Variação Linguística. Em termos de resultados, foi constatado que o conceito de língua subjacente em dois desses manuais didáticos reitera a Ideologia da Padronização, entendendo as variedades linguísticas como "desvios de um padrão", enquanto em um terceiro livro as discussões sobre a temática avançam no sentido de uma compreensão mais social do fenômeno. Espera-se que este estudo contribua como uma interlocução pedagógica que traga à tona reflexão a respeito da compreensão e legitimação de língua como prática social na sala de aula, em especial de cursos técnicos integrados, e o papel da escola no ensino de línguas.
\end{abstract}

PALAVRAS-CHAVE: Variação linguística. Livro didático. Ensino de Língua Portuguesa.

\begin{abstract}
The purpose of this paper is to analyze how three textbooks aimed at high school address the issues of linguistic variation, verifying whether the conception of language as a social practice underlies the textbook approach when dealing with the theme. To do so, it was undertaken a documental analytic research with an exploratory character having as analysis documents textbooks adopted in public schools in the interior of Paraná in PNLD 2015-2017, focusing on the didactic units that deal with Linguistic Variation. In terms of results, it was observed that the underlying language concept in two of these textbooks reiterates the ideology of standardization, understanding the linguistic varieties as "deviations from a standard", while in a third textbook the discussions on the subject move toward a more social understanding of the phenomenon. It is hoped that this study contributes as a pedagogical dialogue that brings to light reflection on the understanding and legitimation of language as a social practice in the classroom, in particular integrated technical courses, and the role of the school in language teaching.
\end{abstract}

KEYWORDS: Linguistic variation. Textbook. Portuguese language teaching.

\section{Introdução}

Desde que a educação básica iniciou seu processo de ampliação de acesso para todos, especialmente para as classes economicamente menos favorecidas, uma série de questões começaram a vir à tona, dentre elas a concepção de língua e o ensino de línguas.

${ }^{1}$ Mestre em Letras pela Universidade Estadual de Maringá, Brasil (2016). Atualmente, cursa doutorado em Estudos Linguísticos pela mesma universidade. Professor do Instituto Federal do Paraná, Brasil. E-mail: rafael.petermann@ifpr.edu.br

${ }^{2}$ Acadêmico de Psicologia pela Universidade Estadual de Londrina, Brasil.E-mail: henrick20132013@gmail.com 


\section{LínguaTec}

Em termos de teorias e de políticas linguísticas, avançou-se na direção de uma compreensão mais social do fenômeno da linguagem, todavia questionamo-nos sobre a maneira como os livros didáticos voltados para o Ensino Médio trataram dessa guinada teórica, que chamamos sociocultural, nos estudos da linguagem. Nesse sentido, a pergunta que nos move neste trabalho é: ao tratar de variação linguística, a concepção de língua como prática social é subjacente à abordagem do livro didático?

As recentes leis de diretrizes e bases da educação, tanto a 5692/71 quanto a 9394/96, fomentaram o processo de democratização e acesso à educação básica para os brasileiros. Com isso classes mais desfavorecidas economicamente começaram a ir à escola. Essas pessoas comumente vinham e vêm de famílias com menor escolaridade $e$, consequentemente, com menor acesso às variedades cultas da língua mais prestigiadas socialmente.

Dessa forma, quando essas pessoas passaram a chegar à escola, tinham sua língua estigmatizada, de maneira que os próprios professores muitas vezes diziam que as formas como elas se expressavam linguisticamente eram "erradas" e sendo assim deveriam ir se corrigindo para conseguirem aprender o jeito "certo" de falar. Isso acabava, de alguma forma, deixando os alunos apreensivos quando precisavam falar ou usar de qualquer artifício linguístico na escola, pois sentiam-se constrangidos em falar algo "errado" e serem corrigidos, assim a maioria optava por uma postura calada em sala de aula, reiterando uma espécie de "pedagogia do silenciamento" (FERRAREZI JR, 2014).

Concomitante a isso, no âmbito dos estudos linguísticos, eram empreendidos estudos voltados a entender a língua de forma contextualizada e com aspectos sociais também sendo considerados nas análises e descrições. Dessa forma, os conceitos de "certo" e "errado" eram problematizados e alguns pesquisadores acabaram chegando a conclusões

que iam além dessa dicotomia. Jung (2010), por exemplo, defende não existir um jeito certo ou errado de falar, o que existiriam são formas de fala adequadas que dependem inteiramente do contexto em que o indivíduo está inserido.

Perfeito (2010), em trabalho didático que remonta a compreensão da linguagem desde os primeiros estudos gregos, passando pelo advento da Linguística Estruturalista, com Saussure, até vertentes mais recentes, observa que a linguagem pode ser definida de 
três modos: (i) como expressão do pensamento; (ii) como instrumento de comunicação e (iii) como forma de interação social.

A linguagem como expressão do pensamento é uma concepção originária da tradição gramatical grega, que só no início do século XX foi rompida. Essa concepção defende a língua como a tradução do pensamento, ou seja, somente por meio dela é possível expressar de forma organizada e articulada os pensamentos. Já a ideia de linguagem como instrumento de comunicação enfatiza que a língua é um conjunto de códigos/signos, internos à mente do falante, que é capaz de transmitir uma mensagem de um emissor a um receptor (PERFEITO, 2010). E, por fim, a terceira construção teórica entende linguagem como forma de interação social, afirmando que a língua é principalmente a interação social entre os interlocutores. Os sujeitos nesse caso são agentes sociais, porque é por meio das interações sociais entre os sujeitos que ocorre a troca de experiência.

Tendo como base a compreensão de linguagem como produto e produtora da interação social e, por isso, uma prática social, verificou-se também uma necessidade de mudar o ensino de línguas na escola. Dessa forma, estudos sobre Variação Linguística começaram a ser integrados ao trabalho em sala de aula, com o intuito de refletir sobre a grande variedade linguística existente, deixando de lado o antigo pensamento dicotômico de "certo" e "errado", e introduzindo uma reflexão acerca dos usos mais ou menos legitimados de forma situada.

Uma questão que nos intriga, entretanto, é que essa concepção de aspecto mais social a respeito da língua é de certo modo nova ou desconhecida pela população não especialista em questões oriundas da sociolinguística. Além disso a mídia, uma parte de gramáticos e professores de Língua Portuguesa, além de certos "literatos", que se sentem guardiões de uma espécie de "patrimônio linguístico" calcado na tradição gramatical normativa, ratificam a língua como sistema concreto, fechado, acabado e hegemônico.

A Ideologia da Padronização da língua (MILROY, 2011) é o principal fator que causou o desenvolvimento da consciência de língua "correta" entre os brasileiros. A maioria das pessoas pensa na língua como um modelo único e pronto que deve ser seguido por todos. Segundo Milroy (2011), tal pensamento gera uma forte crença na correção, isto é, quando existem variações sobre uma palavra ou uma construção, somente uma delas pode ser verdadeira. Isso implica, por exemplo, ser necessário eleger entre “mandioca”, "aipim” e 


\section{LínguaTec}

"macaxeira", qual o único e verdadeiro, e ainda está por trás de disputas que se tornaram anedóticas recentemente como "bolacha" ou "biscoito".

A maioria das pessoas que adere à ideia da padronização não a relaciona com preconceito ou discriminação. Acreditam que os falantes utilizam a língua de forma errada, não considerando as características sociais, econômicas ou culturais dos falantes (MILROY, 2011). Entretanto existiria para eles a oportunidade de, na escola, aprenderem a falar "corretamente". Caso não o façam, isso seria totalmente culpa deles. Nessa visão, portanto, persistiriam as concepções de certo e errado com relação aos usos linguísticos, e a forma correta é a que segue a norma-padrão e qualquer uso linguístico que esteja fora disso seria errado.

Essa concepção social de padronização da língua reflete-se ainda no ensino de Língua Portuguesa nas escolas brasileiras e nos livros didáticos adotados que, embora apresentem variação linguística como conteúdo, aparentemente a Ideologia da Padronização continua subjacente à abordagem. Este trabalho justifica-se, portanto, como uma tentativa de refletir sobre essa questão, problematizando a persistência da Ideologia da Padronização no ensino de Língua Portuguesa que, ainda hoje, reitera condutas de preconceito e/ou de silenciamento de sujeitos externos a essa norma-padrão, carregada de ideologias e de relações de poder.

Desse modo, nosso objetivo é verificar como três livros didáticos destinados para o Ensino Médio trabalham o ensino de variação linguística. Na seção seguinte, apresentamos nosso exercício analítico realizado nos livros didáticos.

\section{Abordagem da variação linguística em livros didáticos}

Nesta seção apresentamos a análise de três livros didáticos destinados para a primeira série do Ensino Médio e que foram indicados pelo Programa Nacional do Livro Didático (PNLD) no triênio 2015-2017. 0 acesso aos livros didáticos se deu por meio de solicitação a uma escola estadual do noroeste do Paraná que forneceu dois títulos de livros didáticos, edição do aluno, mais utilizados nas escolas da região - que chamaremos de Livro 1 e Livro 2. O terceiro livro didático analisado - que chamaremos de Livro 3 -, também 
edição do aluno, foi escolhido por ser o material adotado para as aulas de Língua Portuguesa do IFPR - Campus Paranavaí, instituição em que os autores desenvolveram este estudo.

Após selecionados os materiais didáticos, foi realizada a leitura das unidades destinadas à discussão da variação linguística com ênfase no texto didático de apresentação dos conceitos-chave para os estudantes $e$ as atividades propostas. 0 exercício analítico consistiu em comparar a abordagem dos livros didáticos nos textos de apresentação do conteúdo, as atividades propostas e identificar a concepção de língua subjacente a cada uma delas.

\subsection{Análise do Livro 1}

O primeiro livro analisado é uma edição do manual do aluno, da primeira série do Ensino Médio e foi editado em 2010.

Na seção didática, aquela que é destinada ao estudante, o Livro 1 tem um capítulo inteiro que pretende abordar temas relacionados às noções de variação linguística. Nesse capítulo, os autores apresentam a variação linguística conforme uma tradicional divisão de quatro tipos gerais: sociocultural, histórica, geográfica e situacional.

No primeiro tópico, sobre a variação sociocultural, identificamos um índice que nos permite entendimento sobre a concepção de língua e de norma-padrão reproduzida no material. Ele mostra dois exemplos, um em que o falante utiliza gírias e comete alguns "erros" gramaticais, e outro em que o falante utiliza uma linguagem que tenta se aproximar da gramática normativa. No primeiro exemplo, consta a frase "eles não tinha mais grana pra banca as prestação" e no segundo, "eles não tinham mais dinheiro para pagar as prestações". (LIVRO 1, 2010, p. 225).

Segundo o material, a causa para algumas pessoas se expressarem como o falante do exemplo 1 , se deve pelo fato de que essas pessoas pertencem a grupos sociais mais pobres, de nível de escolaridade baixo e que não conviveram com pessoas de nível cultural elevado, conforme consta na transcrição abaixo de parte do material didático:

Que falantes usualmente empregariam a frase 1 ? E a 2? 
Não é difícil associar a frase 1 a falantes que fazem parte de grupos sociais economicamente mais pobres e de nível de escolaridade mais baixo.

Por outro lado, a frase 2 é mais comum àqueles que tiveram melhores possibilidades sociais e econômicas e, por isso, frequentaram por mais tempo a escola, puderam ter mais contato com a leitura de livros, jornais e revistas e também conviveram com pessoas de nível cultural mais elevado. (LIVRO 1, 2010. p. 255)

Ao fazer essas afirmações, o manual didático parece demonstrar que o nível de escolaridade e o nível econômico são os principais - e talvez únicos - fatores que influenciam a língua dos falantes, excluindo os outros possíveis fatores que podem estar envolvidos como aspectos histórico-culturais da família/comunidade a que o falante pertence. Dessa forma, compreendemos que a obra reitera um dos mitos do preconceito linguístico apresentados por Bagno (2015), o de que as “pessoas sem instrução escolar falam tudo errado."

Com relação às abordagens sobre variação histórica, que consiste nas mudanças que a língua sofre ao longo dos anos, o material dá ênfase à grande integração de palavras originárias da língua inglesa em nosso idioma, como jogging e delete. Segundo o material, ao incorporar essas palavras, a Língua Portuguesa está crescendo e consequentemente se tornando mais rica, e não sendo "apagada". Ele termina afirmando que a língua não é estática, mas sim mutável com o passar do tempo. Na variação geográfica, o livro parece não reiterar antigos preconceitos e este padrão se repete nos demais materiais.

Ao tratar da variação situacional, é possível perceber outro índice que reforça nossa interpretação sobre a concepção de língua subjacente a esta unidade didática. Nela é apresentado um exemplo de um advogado situado em dois contextos sociais distintos: o primeiro em um tribunal atuando juridicamente e utilizando, segundo o livro, o "padrão formal" da linguagem, conforme demonstrado na figura 1. 


\section{Variação situacional}

que um jovem advogado, em um tribunal do júri, diga o seguinte a respeito de ser ouvida pelos jurados:

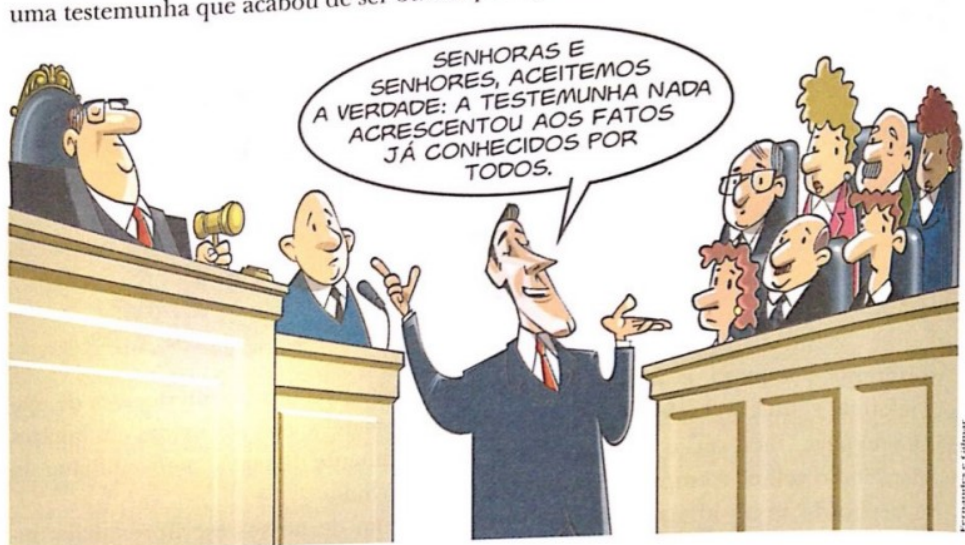

Esse falante se expressou adequadamente, uma vez que empregou o padrão formal de linguagem, em uma situação formal de comunicação. Se, no entanto, ele estivesse batendo um papo com uns amigos a respeito do mesmo fato, ele poderia expressar-se assim:

Figura 1 - Exemplo de Variação Situacional: no tribunal

Fonte: LIVRO 1, $1^{0}$ ano: ensino médio, 2010, p. 228.

Já no segundo quadro, representado na figura 2, este mesmo personagem está em um bar com seus amigos e utiliza agora a "variedade popular da língua”.

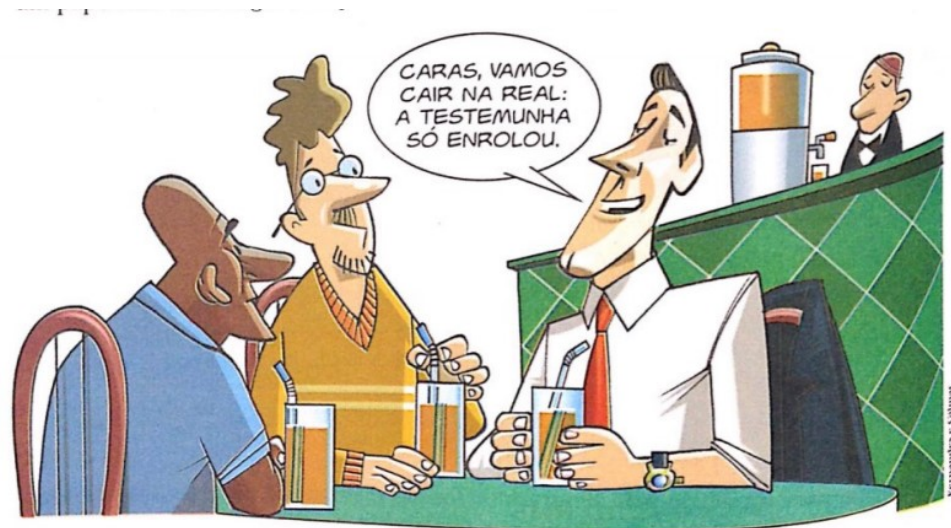

Nesse caso, ele estaria se comunicando em uma situacão informal, usando, adequadr mente, a variedade popular da língua.

Essas diferentes formas de uso do idioma por um mesmo falante, em diferentes situaçôs de comunicação, denominam-se variações situacionais.

Figura 2 - Exemplo de Variação Situacional: no bar

Fonte: LIVRO $1,1^{0}$ ano: ensino médio, 2010, p. 228. 
Embora concordemos que situações formais e informais demandem a mobilização de diferentes variedades linguísticas, conforme demonstrado nas figuras, a oposição simples entre "formal" e "popular" sem maior detalhamento acerca desses conceitos - o material ora analisado não esclarece ao aluno o que seriam os termos "padrão formal" e "variedade popular", tampouco por que em um aparece o termo "padrão" e em outro "variedade" pode gerar uma compreensão reducionista acerca do fenômeno social da linguagem de modo que a categoria "linguagem formal" poderia ser entendida como variedade autônoma e homogênea, enquanto que a formalidade linguística é também atravessada por relações, por exemplo, institucionais, de maneira que uma elocução formal em um tribunal não pode ser considerada do mesmo modo que uma elocução formal em um congresso de medicina. Por isso, para Bagno (2015), por aparentemente não existir um consenso sobre essa terminologia entre os especialistas, utilizá-los poderia acabar confundindo tanto o professor quanto os alunos.

Com relação à seção de atividades dessa unidade didática, notamos que o livro traz vários exercícios, como demonstrado na figura 3 e na figura 4, que solicitam ao aluno classificar o tipo de variação linguística que está presente no texto, e não propõe atividades que solicitem produzir uma reflexão sobre os usos sociais da língua ou sobre o preconceito linguístico.

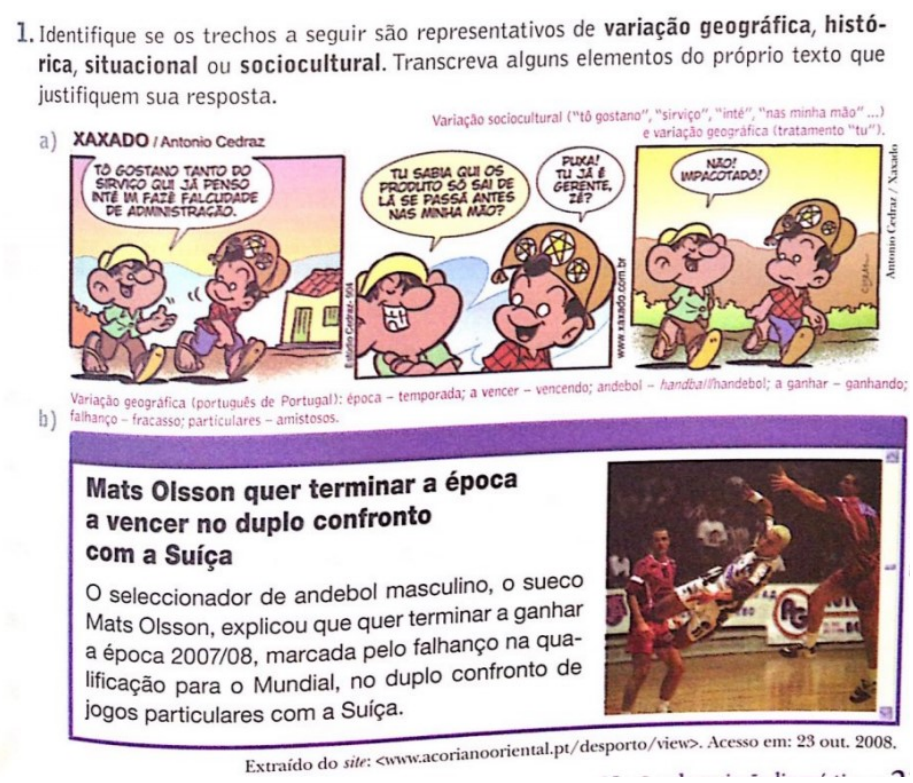

Figura 3 - Exemplo 1 de exercício de classificação de variedades

Fonte: LIVRO $1,1^{\circ}$ ano: ensino médio, 2010, p. 231. 

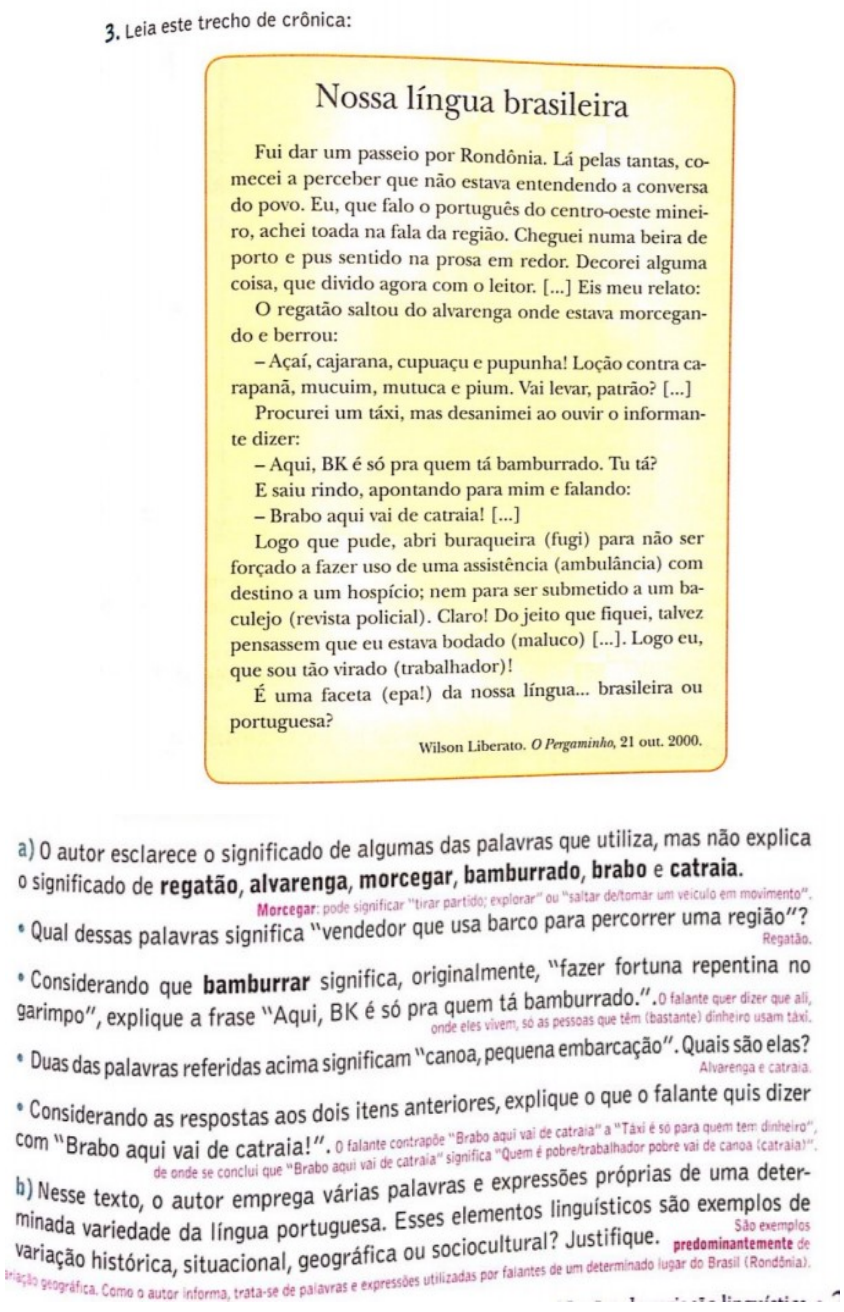

Figura 4 - Exemplo 2 de exercício de classificação de variedades

Fonte: LIVRO $1,1^{\circ}$ ano: ensino médio, 2010, p. 233.

No Livro 1, verificamos que há, então, reiteração de alguma forma da Ideologia da Padronização (MILROY, 2011), pois em vários momentos é possível perceber que a língua é tratada como um sistema único e fechado e que a partir dela derivam as variações. $E$, a partir das atividades que são propostas, o trabalho pedagógico com variação linguística estaria mais relacionado à identificação e à classificação de tipos determinados de fenômenos, do que à reflexão linguística crítica e ao combate ao preconceito linguístico, 0 que remete a uma compreensão mais formalista de ensino de línguas. 


\subsection{Análise do Livro 2}

O segundo livro didático analisado, também edição do aluno e destinado para o primeiro ano do Ensino Médio foi editado em 2013. Neste material, o capítulo que trata dos aspectos de variação linguística é intitulado As variedades linguísticas, e nos primeiros parágrafos da seção é possível identificar a concepção de língua a que se afilia, pois o livro afirma existir uma norma-padrão que serve como "lei que orienta o uso social da língua" $e$ que sua finalidade é "evitar que cada falante use a língua à sua maneira”, conforme demonstrado no trecho a seguir:

Para evitar que cada falante use a língua a sua maneira, em todo o mundo existem especialistas que registram, estudam e sistematizam o que é a língua de um povo em certo momento, o que dá origem à norma-padrão, uma espécie de lei que orienta o uso social da língua. Essa norma-padrão é a que está registrada nos dicionários e nos livros de gramática. (LIVRO 2, 2013, p.79. Grifo no original).

Ainda de acordo com as afirmações do livro didático, dependendo do contexto em que o falante está inserido, ele poderia precisar mais estar ligado à norma-padrão, pois as variedades do português mais próximas a esse padrão seriam indiscutivelmente mais “prestigiadas socialmente". Essas variedades são tratadas no material como "variedades linguísticas urbanas" e associadas a pessoas com alto nível de escolaridade e renda mais alta, como ilustrado no trecho: "As variedades do português que mais se aproximam da norma-padrão são prestigiadas socialmente. É o caso das variedades linguísticas urbanas, faladas nas grandes cidades por pessoas escolarizadas e de renda mais alta." (LIVRO 2, 2013, p.70). Para nós, esse tipo de abordagem ignora os tantos outros possíveis aspectos de ordem histórico-culturais presentes na formação do falante como a família e as instituições das quais participa (igreja, associações, escola, partidos políticos etc).

O excerto abaixo ilustra como o material didático reconhece e apresenta as outras variedades do português mais distantes da norma-padrão, associando-as à linguagem mais rural, menos escolarizada e economicamente inferior.

Outras variedades, faladas no meio rural ou por pessoas não alfabetizadas ou de baixa escolaridade, geralmente são menos prestigiadas e, por isso, frequentemente aqueles que as falam são vítimas de preconceito. Por isso, é importante conhecer a norma-padrão e saber em que momentos seu uso 


\section{LínguaTec}

permitirá que nossos textos ganhem mais credibilidade. (LIVRO 2, 2013, p.80).

Ao tratar das variedades de menor prestígio, o material didático aborda o preconceito linguístico. No entanto, em nosso entendimento, a forma como esse preconceito é abordado aparentemente faz recair a culpa sobre as vítimas, no sentido de que para se evitar o preconceito seria necessário o domínio da língua de prestígio. Para nós, a abordagem que deveria ser dada à questão do preconceito linguístico seria encará-lo como um preconceito social e tentar entender o fenômeno da língua como prática social para vencer o preconceito, trazendo para a sala de aula resultados de pesquisa e discussões que tem reconhecido, documentado e discutido as variedades do português no Brasil.

O livro em questão traz ainda uma caixa de texto com uma curta explicação sobre os termos utilizados no capítulo: variedades linguísticas, norma-padrão e variedades urbanas de prestigio, que transcrevemos abaixo.

Variedade linguisticas são as variações que uma língua apresenta, de acordo com as condições sociais, culturais, regionais e históricas em que é utilizada.

Norma-padrão é uma referência, uma espécie de modelo ou lei que normatiza o uso da língua, falada ou escrita.

Variedades urbanas de prestígio, também conhecidas como norma culta, são as variedades que mais se aproximam da norma-padrão e são empregadas pelos falantes urbanos mais escolarizados. (LIVRO 2, 2013, p. 80).

As informações apresentadas reafirmam a compreensão clássica de variação linguística como um fenômeno que pode ser explicado a partir de categorias como variação social, geográfica, histórica e situacional - conforme constou também no primeiro livro analisado -. Em nosso entendimento, porém, alguns elementos indiciam que uma concepção de língua mais formalista é subjacente a este material. A definição de normapadrão como "modelo ou lei que normatiza o uso da língua falada ou escrita" é o primeiro ponto, pois ao reiterar a ideia de existência de uma norma-padrão, ou língua-padrão (MILROY, 2011), subtende-se que as demais variedades, que em uma compreensão mais sociocultural da linguagem teriam status de patrimônio linguístico, nesta visão seriam concebidas como desvios. Essa afirmação é ratificada no segundo ponto que serve como 


\section{LínguaTec}

índice para esta nossa análise, o fato de que as variedades urbanas de prestígio são aquelas que "mais se aproximam da norma-padrão", ou que dela menos "desviam".

A seção de atividades, assim como no livro analisado anteriormente, traz exercícios que pedem classificação de sentenças e interpretação de frases em contextos diferentes, mas novamente nenhuma questão propõe uma reflexão linguística sobre a variação. Os exercícios repetem o modelo de identificar e classificar, além de perguntas de verificação de decodificação e compreensão de informações do texto base da atividade, conforme ilustrado nas figuras 5 e 6.

Neste livro, notamos, então, uma abordagem marcada pela Ideologia da Padronização (MILROY, 2011). Com uma forte dependência da norma-padrão, que, segundo o próprio material, deve ser um guia para que os falantes não usem a língua "a sua maneira", como se a normatização fosse a única instância orientadora do uso, por exemplo, do português, ignorando instâncias sociais, culturais, históricas, ideológicas, etc. que também exercem influência sobre como as pessoas usam da linguagem para atuarem no mundo.

\subsection{Análise do Livro 3}

O último livro analisado, Livro 3, é também o manual do aluno, destinado para 0 primeiro ano do Ensino Médio e editado em 2013. Este é o material didático adotado pela instituição onde esta pesquisa foi conduzida. Para as asserções analíticas que seguem, olhamos para o capítulo que trata da variação linguística tendo como foco o texto didático que apresenta o conteúdo e as atividades propostas aos estudantes.

Na seção sobre variação linguística que é acessível ao aluno no livro didático, logo pelo seu título, “Uma língua, muitas línguas", é possível notar que ele tende a não conceber a variação linguística como distorções de uma língua padrão, mas entende o Multilinguismo como uma possibilidade de compreensão do fenômeno das variedades, a nosso ver, de forma parecida com o proposto por César e Cavalcanti (2007).

O capítulo começa demonstrando a diferenças entre o português do Brasil e o português de outros países, como Portugal. Isso acontece por meio do poema Lisboa: aventuras, de José Paulo Paes, que retrata as diferentes palavras que se referem a mesma coisa dependendo do país de origem. 
Leia o anúncio:

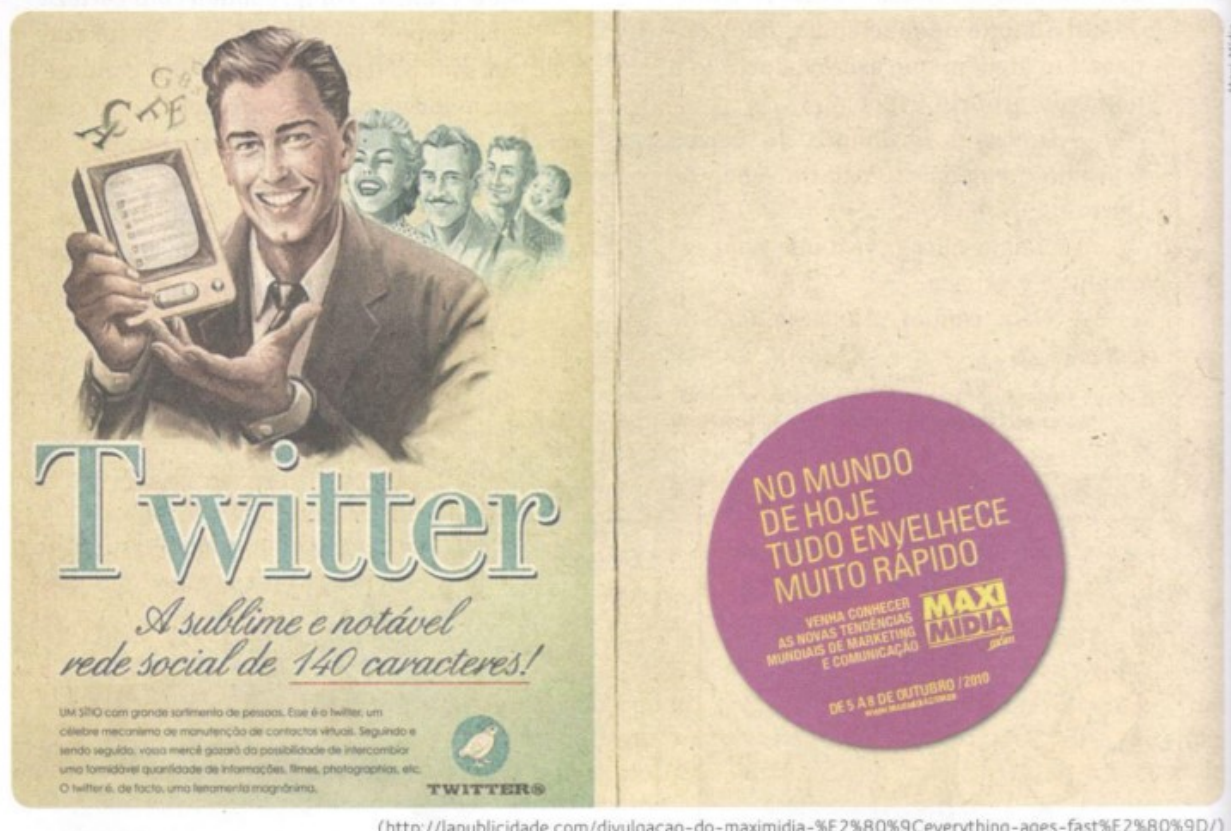

(http//lapublicidade com/divulgacao-do-maximidia-\%E2\%80\%9Ceverything-ages-fast\%E2\%80\%9D/)

1. 0 anúncio divulga um evento que aconteceu no ano de 2010. Entretanto, há no texto elementos que misturam a época atual com outra época, mais antiga.

a) Quais são os elementos não verbais que nos remetem a essa época mais antiga?

b) Quais são os elementos do texto verbal que nos remetem a essa época antiga?

2. Em relação aos termos listados por você no item b da questão anterior, responda:

a) Alguns ainda são utilizados hoje em dia? Quais?

b) Em que situaçōes e por quem eles são utilizados?

3. Apesar de o texto da parte esquerda do anúncio ter a caracterização de uma época antiga, sobre que produto ele fala? Trata-se de um produto antigo?

4. No texto à direita do anúncio, lê-se o enunciado: "No mundo de hoje tudo envelhece muito rápido".

a) Quem é o anunciante?

b) A que público o anúncio é dirigido?

c) Com base nesse enunciado e no estudo feito nas questōes anteriores, justifique a opçāo do anúncio por caracterizar o produto anunciado como algo antigo.

Figura 5 - Exemplo de exercício com classificação de variedades

Fonte: LIVRO 2, volume 1, 2013, p. 84. 
2. Leia o trecho de uma carta de amor escrita por Olavo Bilac, poeta brasileiro que viveu entre o final do século XIX e o inicio do século XX.

Excelentíssima Senhora. Creio que esta carta não poderá absolutamente surpreendê-la. Deve ser esperada. Porque V. Excia. compreendeu com certeza que, depois de tanta súplica desprezada sem piedade, eu não podia continuar a sofrer o seu desprezo. Dizem que V. Excia. me ama. Dizem, porque da boca de V. Excia. nunca me foi dado ouvir essa declaração. Como, porém, se compreende que, amando-me V. Excia., nunca tivesse para mim a menor palavra afetuosa, o mais insignificante carinho, o mais simples olhar comovido? Inúmeras vezes the pedi humildemente uma palavra de consolo. Nunca a obtive, porque V. Excia. ou ficava calada ou me respondia com uma ironia cruel. Não posso compreendê-la: perdi toda a esperança de ser amado. Separemo-nos. [...]

a) Caracterize a variedade linguistica $e$ o grau de formalismo empregados pelo autor do texto.

b) Olavo Bilac viveu no final do século XIX e inicio do século XX. O texto é um bom exemplo de como as declaraçōes amorosas eram feitas na época, nesse tipo de variedade linguística. Colocando-se no lugar do poeta, reescreva o texto, mantendo o conteúdo mas empregando uma variedade linguistica que seria comum entre dois jovens nos dias de hoje. Ao concluir o texto, leia-o para a classe.

Figura 6 - Exemplo de exercício com classificação de variedades Fonte: LIVRO 2, volume 1, 2013. p. 83.

Em seguida, o Livro 3 adota a abordagem tradicional - como os demais materiais - de classificação dos tipos de variedades, dividindo-as em quatro seções: variação histórica, variação regional, variação social e variação situacional. A obra aborda essas divisões de forma breve e sem grandes aprofundamentos. A fim de ilustrar essa afirmação, transcrevemos abaixo as definições apresentadas pelo material didático: 
Variação histórica: o tempo passa, a língua muda.

A língua carrega muitas transformações ocorridas ao longo do tempo. Diversas palavras e construções sofreram mudanças de som, de forma ou de significado. O léxico e os modos de dizer também se modificam constantemente. Essa transformação é chamada de variação histórica.

Variação regional: região e expressão.

A variação regional diz respeito às diferenças que uma língua apresenta nas diversas regiões em que é falada, como observado no poema de José Paulo Pares. A língua portuguesa está presente na Europa (em Portugal), na África (em Angola, Moçambique, Guiné-Bissau, Cabo Verde e São Tomé e Príncipe), na América (Brasil) e na Ásia (no Timor-Leste, nas cidades indianas de Goa, Damão e Diu e na cidade chinesa de Macau). Dá-se o nome de lusofonia ao conjunto de países e lugares que têm o português como língua oficial ou dominante. Mesmo com as inúmeras particularidades - observadas também nas diversas comunidades de falantes do Brasil -, todos falam a mesma língua.

Variação social: somos o que falamos

Os falantes de uma mesma língua são homens e mulheres de diferentes idades, classes socioeconômicas, níveis de escolarização e atividades profissionais. É natural que sua maneira de se expressar seja influenciada por esses diferentes contextos sociais. Esse fenômeno é chamado de variação social.

As diferentes formas de falar contribuem para a construção da identidade dos diversos grupos humanos. Ou seja, por partilhar uma mesma variedade linguística, um conjunto de pessoas se constitui como grupo e constrói uma identidade coletiva.

Variação situacional: língua, para que te quero?

Não se usam as mesmas palavras ou expressões em uma entrevista de empreso, em uma situação de paquera ou para falar com uma criança pequena, sob o risco de não ser atendido, causar impressão negativa ou não alcançar o objetivo pretendido. Um mesmo falante, portanto, usa diferentes variedades linguísticas de acordo com a situação de uso da língua. (LIVRO 3, 2013, p. 199).

Importante destacar que, embora o material traga uma abordagem didática parecida com os demais, apresentando a variação linguística a partir de quatro categorias, ele se difere dos demais aqui analisados, pois avança em uma discussão sobre as noções de certo e de errado nos usos linguísticos dos falantes. Ele afirma que todo falante é um usuário competente da língua, e que o valor de uma variedade está intrinsecamente associado à imagem que se tem dos falantes que a utilizam. Por fim, a obra enfatiza a importância de conhecer as variedades de prestígio que dão acesso a algumas oportunidades profissionais e sociais, conforme ilustrado na transcrição abaixo: 
Norma-padrão, norma culta e adequação

Os membros das comunidades linguísticas naturalmente atribuem diferentes valores aos modos de falar. Do ponto de vista puramente linguístico, não uma forma de falar que seja melhor ou pior do que outra, embora algumas sejam mais adequadas a determinadas situações. Qualquer falante é usuário competente de sua língua materna (aquela que ele aprendeu naturalmente, em sua comunidade linguística). Em geral, 0 julgamento sobre o valor de uma variedade linguística está muito mais associado à imagem que se tem dos falantes ou grupos que a utilizam.

Historicamente, os escritores literários clássicos foram tomados como referencial de uso da língua. Na tradição de ensino, os manuais de gramática procuraram descrever esse modelo (vamos chama-lo de normapadrão) e elevá-lo à categoria de "português correto".

Os estudos linguísticos demonstraram que essa norma padrão era uma idealização: não correspondia sequer aos usos linguísticos registrados nas obras literárias consagradas, ao menos não de maneira uniforme. Ela também não era observada nos veículos conceituados da imprensa nem em obras de referência, como enciclopédias. Hoje há iniciativas de descrição dos usos linguísticos dos falantes considerados "cultos", segundo critérios definidos pelos pesquisadores (por exemplo, nível de escolaridade, hábitos culturais, etc.). Esses usos corresponderiam à efetiva "norma culta" da língua, mas também não representam um bloco uniforme, sendo mais adequado referir-se a eles no plural, como variedades urbanas de prestígio. Adequar-se linguisticamente significa empregar a variedade adequada a cada contexto de uso. Sendo as variedades urbanas de prestígio aquelas que dão acesso a boa parte das oportunidades profissionais $e$ de participação na vida pública, é fundamental conhece-las e se apropriar delas. (LIVRO 3, 2013, p. 199).

O manual didático ainda apresenta uma breve discussão sobre preconceito linguístico. Segundo o material, o preconceito linguístico é fruto de uma série de mitos linguísticos que existem em nossa sociedade, fazendo as pessoas acreditarem que existem línguas melhores do que outras e que existe jeito certo e errado de utilizar a língua. É ainda apresentado que é direito de todo cidadão ter acesso às variedades urbanas de prestígio, entretanto isso não significa que o falante pode ser discriminado por utilizar uma outra variedade. A seguir, transcrevemos o conteúdo relacionado ao preconceito linguístico:

\section{Ação e Cidadania}

Entre as formas de intolerância e discriminação que ainda precisam ser combatidas está o preconceito linguístico. Ele é fruto de uma série de mitos linguísticos que se perpetuaram em nossa sociedade, levando as pessoas a acreditar que existem formas superiores, mais corretas ou mais cultivadas de falar e, por oposição, modos de falar errados, inferiores ou até ridículos. Essa crença é muitas vezes reforçada pela grande imprensa e por publicações que prometem ensinar o falante a não "errar" no uso da própria língua. 
0 valor social atribuído às variedades urbanas de prestígio é inegável e é um direito de todo cidadão brasileiro ter acesso a elas. No entanto, isso não significa que um falante deva ser discriminado ou ridicularizado por fazer uso de uma variedade não padrão. (LIVRO 3, 2013, p.199)

No que tange à parte de exercícios propostos na unidade didática do livro, é possível notar que, assim como os anteriores, há atividades que solicitam ações de identificar e classificar termos e expressões de acordo com as variedades linguísticas trabalhadas. Entretanto o livro não é focado apenas nesse tipo de questão, pois ele propõe discussões que visam entender o porquê de o falante utilizar essa variedade, e, mesmo nas questões de classificação, é solicitada uma justificativa para a resposta. Isso fica evidente no exercício 2 da página 200, em que é apresentado um trecho do roteiro do filme Cidade de Deus, no qual as personagens utilizam uma variedade urbana não prestigiada socialmente. Primeiro o exercício propõe uma classificação dos termos utilizados na história exigindo uma justificativa do aluno, depois requer uma descrição do perfil social das personagens e, por último, solicita que o aluno compare esse texto com o exibido na questão anterior.

Em um outro exercício, o livro propõe também discussão a respeito do mito do português de Portugal ser o "autêntico português" e como esse mito não consegue ser sustentado considerando o fenômeno da variação linguística. Tudo isso é proposto por meio da análise do trecho de uma entrevista com o autor moçambicano Mia Couto. As questões necessitam de uma reflexão do aluno sobre o tema para poderem ser respondidas, e ainda abrem a opção para o professor levantar a discussão sobre a insustentabilidade do mito do "autêntico português" como uma discussão mais abrangente em da sala de aula.

No final do capítulo, é proposto um exercício de debate aos alunos, com base em dois textos acadêmicos que discutem o ensino de gramática na escola. 0 primeiro é do professor de Linguística da UNICAMP, Sírio Possenti; e o segundo é do professor da UERJ e da UFF, Evanildo Bechara. Segundo a proposta, os alunos devem se dividir em grupos e discutir em sala de aula como deveria ser o ensino de Língua Portuguesa nas escolas. 
2. Leia a seguir um trecho do roteiro do filme Cidade de Deus. 0 diálogo entre as personagens se passa no bairro de mesmo nome, no Rio de Janeiro, na década de 1960.

BUSCA-PÉ, o narrador da história, tem nas mãos uma câmera fotográfica profissional. É negro e tem aproximadamente 18 anos. Ao lado dele o amigo BARBANTINHO.

Eles caminham por uma rua do conjunto.

BARBANTINHO

Aí, Busca-Pé...Tu acha mesmo que os cara vão te dar emprego no jornal se tu conseguir tirar essa foto?

BUSCA-PÉ

Eu tenho que arriscar.

[...]

BARBANTINHO (CONT.)

$\mathrm{Na}$ boa, Busca-Pé. Eu acho que os cara do jornal tão de sacanagem. Eles nunca vão te dar emprego.

BUSCA-PÉ

Pó, Barbantinho. Se conseguir essa foto, eu vou ficar na moral com os caras, tá entendendo?

BARBANTINHO Tu tá falando dum jeito que parece até que a gente tá num episódio da Missão Impossível.
BUSCA-PÉ

Pior é que é.

Mantoxans, Bráulio. Roteiro do filme Cidade de Deus. Baseado no romance de Paulo Lins. Dez. 2001. p. 2-3.

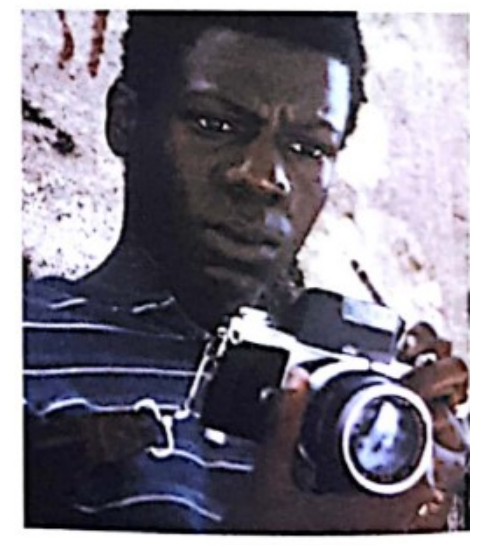

Cena do filme Cidade de Deus (Brasil, 2002), de Fernando Meirelles Na fotografia, 0 ator Alexandre Rodrigues (Busca-Pé). a) Os seguintes termos e expressões, retirados do texto, são exemplos de que tipo de varia.
ção linguística? Justifique sua resposta.

- "os cara"

- "na moral", "na boa"

- "tu" b) Considerando o modo de falar das personagens Barbantinho e Busca-Pé, descreva o
provável perfil social delas.

c) Comparando esse texto com o anúncio do secador de cabelos Gilda, de 1957, qual deles parece mais distante do leitor jovem dos dias de hoje? Justifique sua resposta.

Figura 7 - Exercício com roteiro do filme Cidade de Deus

Fonte: LIVRO 3, volume 1, 2013, p. 200.

São poucos os exercícios em que o aluno precisa reescrever uma frase de acordo com a variedade pedida pelo exercício, já exercícios que estimulam reflexão do aluno sobre a concepção de sua língua e seus usos estão presentes ao longo do capítulo. Isso é um ponto positivo do livro que mostra que consegue questionar a concepção de língua mais aceita pela sociedade, isto é, uma visão mais formalista, e ainda propor uma nova concepção que visa à compreensão da língua como prática social. Além disso, o material interpreta as variedades linguísticas como outras línguas, isso não fica muito claro para os alunos no início do capítulo, mas ao longo dos exercícios o livro vai construindo essa concepção juntamente com o aluno, mostrando a ele que existem diferentes formas de se expressar dentro da mesma língua e que isso não se configura como um erro ou como distorções de 
um padrão, mas é explicado pelos diferentes fatores sociais, culturais e econômicos que atuam sobre a vida dos falantes. O livro finaliza a unidade trazendo uma caixa de texto em que mostra o que seria um falante competente da língua, sendo descrito como aquele que é um poliglota em sua própria língua sendo capaz de se adequar linguisticamente ao contexto no qual está inserido. A transcrição dessa caixa de texto é apresentada a seguir:

Nenhuma variedade linguística é superior a outra. O falante competente é aquele que consegue ser um poliglota em sua própria língua, ou seja, que conhece muitas variedades linguísticas - inclusive as variedades urbanas de prestígio - e é capaz de escolher a mais adequada a cada contexto ou situação de uso. (LIVRO 3, 2013, p. 204).

\section{Considerações Finais}

Neste trabalho, tivemos como objetivo analisar de que forma três livros didáticos do Ensino Médio selecionados abordam a variação linguística. Entendemos que principalmente os Livros 1 e 2 estão de alguma maneira ligados à Ideologia da Padronização (MILROY, 2011), pois parecem conceber a língua como um sistema único e fechado que é exterior ao falante, isto é, resume-se a uma "norma".

Isso acontece uma vez que a utilização de uma abordagem de ensino, que mais visa ao reconhecimento e classificação das "variedades" do que a reflexão acerca da existência e da persistência dos fenômenos linguísticos, leva a considerar que esses livros enxergam a variação linguística como distorções de um padrão ilusório da língua, sendo inclusive defendida pelo Livro 2 a necessidade de uma norma-padrão que possa servir como um guia para evitar o uso desregulado por parte dos falantes.

Pensamos que os livros didáticos poderiam abordar as variedades linguísticas de uma forma que legitimasse as variedades como línguas, evitando assim a clássica concepção do "certo" e "errado". Dessa forma, os falantes aprenderiam as variedades de prestígio com o objetivo de ampliar o seu repertório linguístico e não de substituí-lo.

A forma escolhida para apresentar o fenômeno da variação linguística no Livro 1 parece indicar que algumas variedades podem ser colocadas acima de outras. E a utilização de alguns termos, como norma-padrão, configura-se como um problema, pois a não definição desses termos por parte dos livros acaba confundindo tanto o aluno quanto 0 professor, já que não existe um consenso acerca desses termos. Com relação às atividades 
propostas para os estudantes, estas resumem-se a exercícios de identificação e classificação do tipo de variação linguística presente em alguns textos, produzindo pouca ou nenhuma reflexão linguística.

Da mesma forma acontece com o Livro 2. A forma com que trata a variação linguística indica que este concebe as variações linguísticas como sendo uma distorção. Este livro trata de forma breve o preconceito linguístico, e sua abordagem faz parecer, conforme discutimos, que a culpa de as pessoas que utilizam formas de expressão linguística menos legitimadas sofrerem preconceitos linguísticos é delas mesmas por não terem seguido a norma-padrão, sendo isso uma das consequências da Ideologia da Padronização apontada por Milroy (2011). No que tange às atividades propostas, assim como o Livro 1 , este apresenta exercícios que centram-se mais na identificação e classificação de tipos de variação, além de ênfase na decodificação e compreensão dos textos utilizados nas atividades.

O Livro 3, por sua vez, assim como discutimos, avança em alguns pontos importantes na discussão sobre variação linguística, pois legitima as variedades linguísticas trazendo discussões a respeito de norma-padrão, erro etc. Ele também não se limita a exercícios que exigem apenas a classificação e a identificação de variedades linguísticas, mas tenta propor exercícios que promovam uma discussão e uma reflexão acerca do uso da língua e da existência das variedades.

O Livro 3 a nosso ver, cumpre de forma mais satisfatória a abordagem da variação linguística concebendo a língua como prática social. Desta feita, esta concepção de língua subjacente ao livro está de acordo com a concepção presente no ementário das disciplinas de Língua Portuguesa I dos cursos técnicos integrados no IFPR Campus Paranavaí, local em que este estudo foi desenvolvido.

Cumpre destacar nestas considerações finais que a compreensão de língua como prática social, isto é, como produto e produtora das interações humanas e, assim, como forma de agir no mundo é coerente com a ideia de educação emancipadora que se pretende em um curso técnico integrado em nossa instituição, pois, para além de uma educação linguística que invista nos estudantes um olhar situado para a linguagem no mundo do trabalho; é também tarefa das disciplinas de línguas, em especial de Língua 
Portuguesa, construir uma consciência linguística crítica que tenha como ponto de partida e de chegada a cidadania.

\section{REFERÊNCIAS}

BAGNO, Marcos. Preconceito linguístico. 56 ed. São Paulo: Parábola Editorial, 2015.

CÉSAR, A; CAVALCANTI, M. Do singular ao multifacetado: o conceito de língua como caleidoscópio. São Paulo: Mercado de Letras, 2007.

FERRAREZI JR, C. Pedagogia do silenciamento: a escola brasileira e o ensino de língua materna. São Paulo: Parábola Editorial, 2014.

JUNG, N. M. A variação linguística e o texto na sala de aula. 1 ed. Maringá: UEM, 2010.

MILROY, J. Ideologias linguísticas e as consequências da padronização. In: LAGARES, X. C; BAGNO, M. (Org.) Políticas da norma e conflitos linguísticos. São Paulo: Parábola, 2011.

PERFEITO, A. M. Concepções de linguagem, teorias subjacentes e ensino de língua portuguesa. In: MENEGASSI, R. J; DOS SANTOS, A. R; RITTER, L. C. B. (Org.) Concepções de linguagem e ensino. Maringá: Eduem, 2010, p. 11- 38.

Data de submissão: 19/06/2018. Data de aprovação: 13/11/2018. 